\title{
Sir Leonard Parsons of Birmingham (1879-1950) and antenatal paediatrics
}

\section{P M Dunn}

Born and educated in the Midlands, Sir Leonard Parsons made major contributions to the field of paediatrics in that area and played a leading role in the regional organisation of this specialty throughout the United Kingdom in the later years of his life. He was a founder member and later President of the British Paediatric Association, and later became Vice-President of the International Pediatric Congress and the President of the paediatric section of the Royal Society of Medicine.
Correspondence to: PM Dunn, Department of Child Health, University of Bristol, Southmead

Hospital, Bristol BSIO 5NB, UK

Correspondence to: Professor Dunn:

P.M.Dunn@Bristol.ac.uk eonard Gregory Parsons was born in Kidderminster on 25 November 1879. ${ }^{12}$ His parents, Theophilus and Sarah, came of Worcestershire stock and were staunch Methodists. Leonard grew up in Aston and went to King Edward VI Grammar School, where he shone at sport, particularly rugby and sprinting. In 1896 he studied zoology at Mason College, Birmingham but then turned to medicine, winning a scholarship and qualifying MB, BS (London) in 1903. During the next seven years he worked at the Hospital for Sick Children and at the Brompton in London, and obtained the MRCP and MD (1908). He then

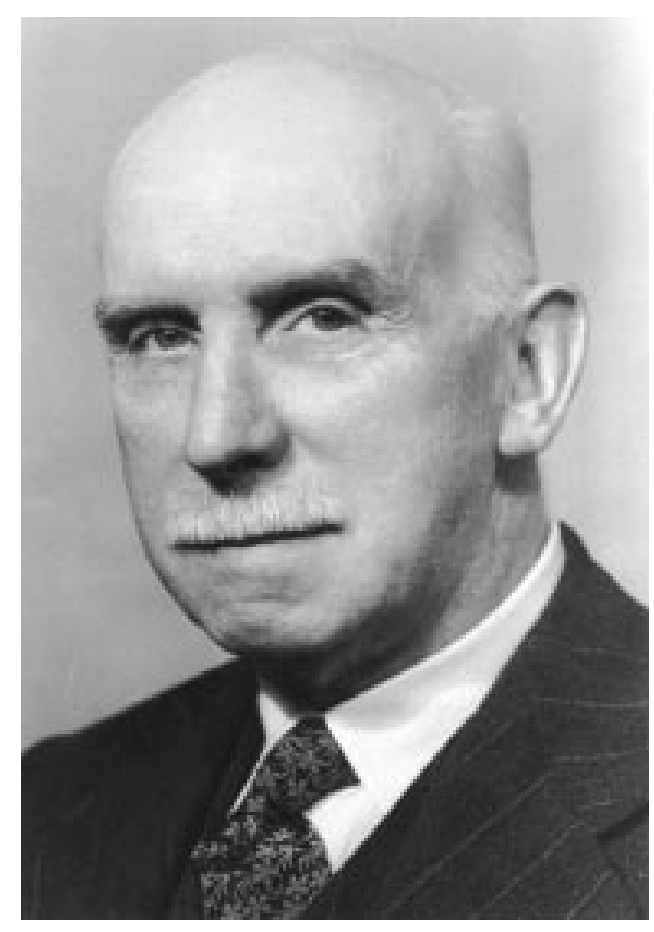

Figure 1 Sir Leonard Parsons (1879-1950). practised for a time in Bromsgrove. Already though he was determined to become a paediatrician, still a very neglected area of medicine. In 1908 he married Ethel Mantle, the daughter of a Methodist minister, and they had a son, Clifford, who subsequently became a distinguished paediatric cardiologist, and also a daughter.

In 1910 Parsons was appointed physician to the outpatients of the Birmingham Children's Hospital. Within a short time he had made his mark both as a clinician and researcher, and in 1914 the new post of lecturer in the diseases of children and paediatrics was created for him by the University of Birmingham. The first world war intervened and he saw service as a major in the RAMC in Greece and Serbia for which he received the Serbian Order of St Sara in 1917. Returning to Birmingham Children's Hospital in 1918, Parsons resumed his lecturer duties. In 1923, the year he became FRCP, he gave the Gaulstonian Lecture of the Royal College of Physicians on the wasting diseases of infancy and in 1928 the Ingleby Lectures on rickets and allied disorders. ${ }^{3}$ The following is an extract:

\section{ON RICKETS ${ }^{3}$}

"... recent advances in our knowledge have shown that rickets is a disorder of calcium and phosphorus salt metabolism, usually the result of defective absorption of these elements from the bowel; further, that this defective absorption is due either to an inefficient supply of these elements, or of some activating body in the tissue fluids; that this body is probably vitamin $D$, which in its turn is derived from the alimentary canal, or synthesised by the action of ultra-violet rays on sterols in the skin; but that occasionally the faulty metabolism may be entirely endogenous in origin, as occurs in renal rickets; and finally, that growth is an essential for the development of rickets.

Although rickets existed before Glisson's time it certainly increased markedly after his day, and became almost universal in some grades of urban society, especially in districts like our own Black Country and Glasgow. We must, however, remember that except for the empirical discovery of the curative effects of cod-liver oil some hundred years ago, our knowledge of the disease advanced very little until the last few years. Although there are still many 
gaps in our complete knowledge of the disorder, recent researches have put us in possession of information that should allow us completely to eradicate all ordinary rickets. Already its incidence and severity are declining, and we can look forward with sure and certain hope to the day, perhaps no further distant than the tercentenary of Glisson's work, when rickets will have become one of that small but increasing number of diseases which possess a great interest for the historian but happily present no terrors of ill-health for the patient and no cause for anxiety on the part of the doctor."

In 1928 Parsons was appointed to the new chair of paediatrics and child health in Birmingham and the following year he was made subdean of the medical faculty. He argued (1933) that the study of children's diseases was not a postgraduate specialty but rather general medicine and surgery applied to a special age, period of growth, and development, the like of which was unknown at any other time. In 1934 he expressed dissatisfaction with the curriculum and was responsible for introducing paediatric clinical clerking for medical students. The following year he was active in establishing the diploma of child health of the Royal Colleges. His textbook written with Seymour Barling and published in 1933, Diseases of infancy and childhood, ${ }^{4}$ became a standard work. He was also very involved during the 1930s in the development of the new medical school on the Queen Elizabeth Hospital site.

Parsons gained an international reputation for his research. He wrote: "all those who desire to advance knowledge by experiment must exploit their imagination and be constantly asking 'why' and 'how' ". He agreed with Eddington that "progress is marked not so much by the problems we are able to solve as by the questions we are enabled to ask". He helped to raise paediatrics to a high scientific level, opening many new fields of investigation. He was one of the first to utilise biochemical studies and constantly emphasised the importance of postmortem examination in early life as a means of elucidating the primary pathology of disease. As he wrote:

\begin{abstract}
"The problems offered for solution are simpler, in the sense that they are more straightforward. Disease can here be studied in its frankest and least complicated forms. It is not modified by the wear and tear of life, nor complicated by the scars of old wounds, which tend to become more frequent as the years pass by. The infant more closely approaches the experimental animal than any other known species."
\end{abstract}

The main thrust of Parsons' research was on nutrition, coeliac disease, and rickets. In 1933 he was the first to treat a case of scurvy with synthetic ascorbic acid, prepared by Sir Normal Haworth, professor of Biochemistry in Birmingham. Another of Parsons' special interests was a condition that later came to be known as Rhesus haemolytic disease of the newborn. With Diamond, Blackfan, and Baty of Boston, his group in Birmingham was the first to show in 1933 that hydrops foetalis, icterus gravis, and haemolytic anaemia of the newborn were different manifestations of the same underlying condition. However, whereas the Boston school believed that this underlying condition was a primary erythroblastosis, Parsons and his colleagues were convinced that the primary factor was haemolysis and that the erythroblastosis was just a compensating mechanism. They also appreciated that severe icterus gravis might be accompanied by liver damage and even cirrhosis, as well as by kernicteric brain damage. ${ }^{5}$

In 1928 Parsons became one of the founder members of the British Paediatric Association. In 1930 he was elected Vice-President of the International Pediatric Congress in
Stockholm and the following year President of the paediatric section of the Royal Society of Medicine. He was instrumental in creating the Birmingham Institute of Child Health in 1930 with a view to integrating efforts to prevent as well as cure the problems of childhood. Throughout the 1930s he improved the clinical facilities and teaching at the Birmingham Children's Hospital as well as building up research there. The advent of the second world war in 1939 found him carrying multiple responsibilities as Dean of the Medical Faculty, as a member of the GMC, as Councillor of the RCP, and as medical officer for the Ministry of Health for the Midland Region. In the latter capacity he was responsible for all casualties as well as administration problems in the region.

In the last decade of his life, Parsons played a leading role in the regional organisation of paediatrics throughout the United Kingdom. He also turned to what is now termed perinatal medicine. In 1943 the Royal College of Physicians invited him to give the first Charles West lecture. The title of his address was Prevention of neonatal disease and death. ${ }^{6}$ He began by lamenting the loss of 43000 neonatal lives each year in the United Kingdom, mainly as a result of asphyxia, birth injury, prematurity, and infections. He deplored the general neglect of this time of life by British paediatricians and emphasised the fact that the mother and baby formed a biological unit whose interests should never be separated. Of particular interest were his comments on the care of low birthweight infants:

\section{CARE OF PREMATURE INFANTS ${ }^{6}$}

"The lowest (mortality) figures known to me were achieved in a London hospital during the war, and over a period that involved extensive air attacks. In a group of 185 (premature) babies under the care of Elaine Field (1943) at University College Hospital the mortality rate was $8.1 \%$. When it is realised that these infants were delivered in overcrowded, hot and stuffy wards, lighted by artificial light; that they were nursed in a side room which also functioned as a sister's office and to which students, nurses and medical staff had free access, and that the degree of humidity was determined not by elaborate machinery but by the breath of the inmates, I think it will be agreed that it is difficult to praise adequately this superb medical and nursing effort. Field attributes her results to three things; a high standard of nursing; the use of breast milk; the minimum handling of the infant. If breathing were poor or blue attacks occurred, oxygen with $5 \% \mathrm{CO}_{2}$ was given nasally. . . No-one except the doctor and the nurse touched the infants; masks and gowns were worn by the nurse but rarely by the medical staff . . . Field seems to have proved that skilled paediatricians can almost solve the problems of the premature infant, but the available evidence shows that an improvement in the nutrition, social conditions and general health of expectant mothers will diminish the premature birth-rate, and that the close co-operation of obstetricians with paediatricians who have had experience of neonatal conditions is essential for the adequate treatment of prematurity ... . a greater saving of life can take place at this period than at any other and most premature children who survive become normal children ... (But) foetal and neonatal mortality are not likely to fall until the standard of midwifery and paediatric skill is raised..."

Two years later in 1945 Parsons wrote in the foreword to Dr Victoria Mary Crosse's Prematurity": "This book, which is 
unique in British literature, will prove invaluable to obstetricians, paediatricians, general practitioners and nurses, and if the advice given by Dr. Crosse is put into practice on anything like a considerable scale the long overdue reduction in neonatal mortality will have begun."

In 1945 Parsons was invited to give the Blair-Bell Memorial lecture to the RCOG. ${ }^{8}$ He said:

\section{ANTENATAL PAEDIATRICS ${ }^{8}$}

". . . it is only since I have been engaged in the study of neonatal disease and death that I have realised how greatly I have been handicapped by my ignorance of midwifery. Paediatricians... have been somewhat slow in realising the great influence, for good or for ill, of antenatal conditions on the foetus, and although they are concerned with the production of healthy children, they have shown strangely little concern about the state and efficiency of the "factories" in which these products are made ... The paediatricians of the future must be concerned with the well-being of the child from the moment of its conception and sometimes even before that event..." $\mathrm{He}$ ended his lecture: "When obstetricians, paediatricians and social workers combine together ... the future will indeed be radiant with promise. The full results of such a partnership will not be seen in my life time, but possibly from some Elysian field in company with Blair-Bell I may be permitted to witness them."

The following year he reiterated the above theme in his Blackader Lecture to the Canadian Medical Association with the title "The effect of antenatal conditions on the newborn infant"."

Parsons was tall, thin, and remarkably athletic. He enjoyed many sports. A simple, shy, ascetic, and humble man with deep religious convictions, he was gentle, kind, had a quick sense of humour, and delighted in the company of a wide circle of friends. He had a deep interest in the individual and inspired admiration and affection. He was calm, imperturbable, and radiated a sense of security. He had an eminently practical outlook. Immensely hard working, capable of sustained concentration, and with a very retentive memory, he was quick to grasp the essentials of a problem and was not prepared to accept second best. His enthusiasm, combined with tact, patience, and determination, usually enabled him to reach his goal. There was a freshness about him, and a spirit of open mindedness and self criticism. He never sought publicity. He had great clinical acumen and remarkable skill with children combined with quite exceptional paediatric experience and an original talent for scientific investigation. He also had great administrative ability. His intelligence, wisdom, and vision, his honesty of purpose, and his humility and humanity made him an outstanding leader in paediatrics and child health, as well as a prophet for perinatal medicine in the years to come.

Many honours were bestowed on Parsons: Presidency of the BPA (1942-1945), the Moxon Medal of the RCP (1942), FRCOG en eundem (1947), FFR (1947), and FRS (1949). In 1945 a wing of the Birmingham Children's Hospital was named after him. On his retirement in 1946, he was knighted for services to children during the war. In 1950 he was invited to give the annual RCP Harveian oration. ${ }^{10}$ Like Harvey he exhorted his colleagues "to search out and study the secrets of nature, by way of experiment" and "to continue in mutual love and affection". Two month's later on 17 December 1950 he died suddenly from a cerebral haemorrhage at his home in Four Oaks. He was 71. In his memory, the chair of paediatrics and child health in the University of Birmingham was named after him

\section{REFERENCES}

1 Smellie JM. Obituary: Sir Leonard Gregory Parsons. Arch Dis Child 1951;20:1-3.

2 Neale AV. Sir Leonard Parsons (1879-1950). J Pediatr 1956:48:530-8.

3 Parsons LG. Some recent advances in our knowledge of rickets and allied diseases. Ingleby Lectures. Lancet 1928;ii:433-8, 485-9.

4 Parsons LG, Barling S, eds. Diseases of infancy and childhood. Oxford: Humphrey Midford, 1933.

5 Parsons LG. The clinician and the Rh factor. Lancet 1947;i:815-20.

6 Parsons LG. Prevention of neonatal disease and death. Lancet 1944;i:267-72.

7 Crosse VM. The premature baby. London: Churchill Livingstone, 1945.

8 Parsons LG. Antenatal paediatrics. First Charles West Lecture. J Obstet Gynaecol 1946;53:1-16.

9 Parsons LG. The effect of antenatal conditions on the newly-born child. 5th Blackader Lecture. Can Med Assoc J 1946;55:327-36.

10 Parsons LG. The influence of Harvey and his contemporaries on paediatrics. Harveian oration, 1950. London: Headley Bros Ltd, 1950. 